\title{
Root Distribution and Its Impacts on the Drought Tolerance Capacity of Hybrid Rice in the Sichuan Basin Area of China
}

\author{
Xuechun Wang ${ }^{1, *,+}$, Naseem Samo ${ }^{1,+}$, Lamei Li ${ }^{1}$, Mengran Wang ${ }^{1}$, Muslim Qadir ${ }^{1}$, \\ Kaifeng Jiang ${ }^{2}$, Jian Qin ${ }^{2}$, Fahd Rasul ${ }^{3}$, Guotao Yang ${ }^{1}$ and Yungao $\mathrm{Hu}^{1}{ }^{1} *$ \\ 1 College of Life Science and Engineering, Southwest University of Science and Technology, \\ Mian Yang 621010, China; samonaseem@hotmail.com (N.S.); 18308462738@163.com (L.L.); \\ wmrtutu22@163.com (M.W.); hongni2005@sohu.com (M.Q.); yangguotao2377893@163.com (G.Y.) \\ 2 Key Laboratory of Southwest Rice Biology and Genetic Breeding, Ministry of Agriculture, \\ Institute of Rice and Sorghum, Sichuan Academy of Agricultural Science, Deyang 618000, China; \\ jiangkf67@126.com (K.J.); qinj1989@163.com (J.Q.) \\ 3 Agweathernet, Washington State University, Prosser, WA 99350, USA; drfahdrasul@gmail.com \\ * Correspondence: xuechunwang@swust.edu.cn (X.W.); huyungao@swust.edu.cn (Y.H.); \\ Tel.: +86-137-7800-5567 (X.W.); +86-130-8641-0010 (Y.H.) \\ + These authors contributed equally to this work.
}

Received: 11 January 2019; Accepted: 6 February 2019; Published: 12 February 2019 updates

\begin{abstract}
Drought is one of the major factors limiting rice yield worldwide. A total of 46 hybrid rice varieties were chosen to investigate their root distribution and their response to drought. A field experiment was carried out in a dry shed building to evaluate the drought tolerance capacity of hybrid rice varieties on the basis of CTIRDE (complex tolerance index of rice under drought environment) values. Next, the experiment was conducted in a specially designed pot system and seed bags to analyze the root distribution and activity of antioxidant enzymes in different rice varieties. Moreover, the DEEPER ROOTING 1 (DRO1) gene was sequenced to elucidate its role in the root distribution of typical rice varieties. On the basis of CTIRDE values, the 46 hybrid rice varieties were classified as tolerant (CTIRDE $\geq 0.75)$, semi-tolerant $(0.75>$ CTIRDE $>0.65)$, or sensitive (CTIRDE $\leq 0.65)$ to drought stress. The tolerant varieties (Chuanguyou208 and Deyou4727) displayed a significantly larger length, had higher number and weight of roots in the $30-50 \mathrm{~cm}$ soil layer, and exhibited a significantly higher activity of Superoxide dismutase (SOD) and Peroxidase (POD) enzymes in roots during the drought stress period. The DRO1 gene sequencing results revealed that the tolerant and sensitive varieties exhibited a single-nucleotide polymorphism (SNP) in the 3-exon region, and the tolerant varieties (Chuanguyou208 and Deyou4727) exhibited a larger root growth angle with the horizontal axis, hence developing a deeper root system as compared with the other two group varieties. A significant correlation was found not only between the DRO1 gene and root distribution but also between DRO1 and the activity of SOD and POD enzymes. Conclusively, as a key feature, a deep root system enabled tolerant rice varieties (Chuanguyou208 and Deyou4727) to avoid drought stress by absorbing more water stored in deep soil layers. The root distribution, activity of POD and SOD enzymes in roots, and DRO1 gene can be used to screen tolerant rice varieties that can survive better under drought stress during the seedling stage of rice growth.
\end{abstract}

Keywords: rice; drought; CTIRDE; root distribution; DRO1 


\section{Introduction}

As one of the serious stress factors for rice growth, drought has caused a $25.4 \%$ reduction in rice yield over the last 20 years [1]. South and Southeast Asia and Sub-Saharan Africa (SSA) suffered more drought stress than other regions in the world. In China, the average annual drought-affected land is as much as 26.67 million hectares, lowering food production by $70-80$ billion $\mathrm{kg}$ over the last 30 years [2]. Drought is also a major factor limiting rice production in SSA [3]. In SSA, rice is more susceptible to drought events because its cultivation largely depends on rainwater; therefore, even a mild drought significantly reduces the productivity of rice [4].

Several strategies have been used to identify rice varieties that can survive better under drought stress, including morphological, physiological, and biochemical responses of plant in a drought environment [5-7]. When rice is exposed to drought stress, it shows a reduction in plant height, wilting, leaf rolling, leaf senescence, stomatal closure, decreased leaf elongation, and lower dry matter production [6-9]. These variations differ significantly among different rice varieties $[6,7,10,11]$; however, it is difficult to identify resistant rice varieties by any one of these agronomic traits. Root length and distribution is also one of key characteristics for screening drought tolerance in rice. Under drought stress, upland rice develops deep and thick root systems in order to improve the hydraulic properties of its roots $[9,12]$. These features greatly enhance the drought resistance of upland rice varieties by allowing the absorption of more water stored in deep soil layers [13-16]. The DRO1 gene was identified from recombinant inbred lines (IK-RILs) derived from a cross between the shallow-rooting cultivar IR64 and the deep-rooting cultivar Kinandang Patong. Introducing DRO1-kp into the shallow-rooting rice cultivar IR64 increased deep rooting in the resulting line, which enabled it to avoid drought through absorbing water from deep soil and maintain high yield performance under drought conditions $[14,16]$.

Rice has an effective antioxidant enzymatic defense system including Superoxide dismutase (SOD), Peroxidase (POD), and Catalase (CAT) enzymes. Under various environmental stresses, antioxidant enzyme and metabolite content increases, and comparatively higher activity of this defense system has been reported in tolerant cultivars than in susceptible ones [17]. During drought stress, certain studies reported enhanced CAT, POD, and SOD activity [7], whereas in others, a down-regulation in their activity was observed; for example, Chutipaijit [18] reported lower SOD activity in tolerant varieties than in sensitive varieties. These differences in the response of antioxidant enzyme activity may be related to the stress severity and duration [19] and the drought tolerance capacity of the plant species [20]. Generally, it is acknowledged that maintenance of a high level of antioxidant enzyme activities may contribute to drought tolerance by increasing the capacity of protection mechanisms against oxidative damage.

The objectives of present research are (1) to clarify the role of root distribution and antioxidant enzymes in the drought tolerance capacity of examined varieties; (2) to evaluate the role of DRO1 in the variation in root distribution of typical rice varieties; and (3) to identify the varieties which are best capable of surviving better in drought stress regions and to provide a theoretical foundation for hybrid rice breeding.

\section{Materials and Methods}

\subsection{Materials and Experimental Design}

A total of 46 rice genotypes (Oryza sativa) (Table 1) were collected to examine their response under drought stress. From 2016 to 2017, the experiment was conducted in a dry shed building and in a specially designed pot system (China National Invention Patent, ZL201610221861.1) (Figures S1 and S2) which can build drought stress quickly for rice and allows convenient access to rice roots. The soil used in this study was typical sand-loam soil which is $62 \%$ sand, $25 \%$ silt, and $13 \%$ clay. In order to reduce the impacts of nutrition stress on rice growth, $13.5 \mathrm{~g}$ nitrogen, $5.3 \mathrm{~g}$ phosphorus, and $3.6 \mathrm{~g}$ potassium were mixed into the soil for each pot. 
Table 1. Information on the 46 rice varieties collected in Sichuan Province, China for drought screening.

\begin{tabular}{|c|c|c|c|c|c|}
\hline Number & Genotype & Male $\times$ Female of F1 Hybrid & Number & Genotype & Male $\times$ Female of F1 Hybrid \\
\hline 1 & Yixiang4245 & Yixiang1A $\times$ Yihui4245 & 24 & Tianlongyou1340 & Tianlong13A $\times$ Tianlonghui140 \\
\hline 2 & Jiayou 727 & Jialing1A × Chenghui727 & 25 & Tianlongyou140 & TianlongS × Tianlonghui140 \\
\hline 3 & Chuannongyou 498 & Chuannong1A $\times$ Shuhui498 & 26 & Tianlongyou 872 & Tianlong8A $\times$ Tianlonghui72 \\
\hline 4 & Deyou4923 & Dexiang074A $\times$ R4923 & 27 & jingyou781 & Jing7A $\times$ Dehui381 \\
\hline 5 & Rong18you307 & Rong18A × Ronghui307 & 28 & Tianlongyou 540 & Long5A $\times$ Tianlonghui140 \\
\hline 6 & Dexiang4103 & Dexiang074A × LuhuiH103 & 29 & Byou5761 & B501A $\times$ Xikehui 4761 \\
\hline 7 & Huaxiany357 & HuaxiangyouA $\times$ Mianhui357 & 30 & Longyou450 & Longxiang $4 \mathrm{~A} \times$ Tianlonghui1250 \\
\hline 8 & Guangyou2928 & Guangkang13A $\times$ xikehui2928 & 31 & Chuanyou5778 & Chuan106A × Nanhui5778 \\
\hline 9 & Nei6you611 & Neixiang6A $\times$ Mianhui138 & 32 & Byou 2727 & B213A $\times$ Chenghui727 \\
\hline 10 & Chuanyou5727 & Chuan345A $\times$ Chenghui727 & 33 & Zhufengyou 4720 & Zhufeng4A $\times$ Xikehui720 \\
\hline 11 & Rong18you447 & Rong18A × Ronghui447 & 34 & Byou3446 & B395A × Xikehui3446 \\
\hline 12 & Yixiangyou1108 & Yixiang1A $\times$ Yihui1108 & 35 & Chuanyou1288 & Chuan106A $\times$ Xikehui1288 \\
\hline 13 & Fyou 498 & FS3A $\times$ Shuhui498 & 36 & Jinyou1720 & Jin1A $\times$ Xikehui720 \\
\hline 14 & Deyou 4727 & Dexiang074A $\times$ Shuhui727 & 37 & Byou 4446 & B4A $\times$ Xikehui3446 \\
\hline 15 & Luyou 257 & Lu98A $\times$ Shuhui257 & 38 & Rongyou3268 & Rong3A $\times$ Xikehui1288 \\
\hline 16 & Chuanguyou208 & ChuanguA $\times$ Shuhui208 & 39 & Byou727 & B1A $\times$ Chenghui727 \\
\hline 17 & IIyou498 & II-32A $\times$ Shuhui498 & 40 & Guangyou3446 & Guangkang13A $\times$ xikehui3446 \\
\hline 18 & Nei6you538 & Neixiang6A × Shuhui538 & 41 & Byou2761 & B2A $\times$ Xikehui4761 \\
\hline 19 & Chuannongyou298 & Chuannong2A $\times$ Shuhui498 & 42 & Byou 2909 & B2A $\times$ Xikehui9909 \\
\hline 20 & Chuannongyouhuazhan & Chuannong1A $\times$ Huazhan & 43 & Byou1288 & B1A $\times$ Xikehui1288 \\
\hline 21 & Chuannongyou3203 & Neixiang6A $\times$ Luhui9 & 44 & Byou 4928 & B4A $\times$ Xikehui2928 \\
\hline 22 & Nei5you317 & Neixiang5A $\times$ Neihui3317 & 45 & Byou5768 & B501A $\times$ Xikehui768 \\
\hline 23 & Neixiang7you317 & Neixiang7A $\times$ Neihui3317 & 46 & Gangyou725 & Gang46A $\times$ Mianhui725 \\
\hline
\end{tabular}

All varieties examined in this research are $\mathrm{F} 1$ hybrids; left of $\times$ is the male parent of the $\mathrm{F} 1$ hybrid, right of $\times$ is the female parent of the $\mathrm{F} 1$ hybrid. 
The field experiment was performed in a dry shed building at the Rice Research Institute Southwest University of Science and Technology (RRISWUST), Mianyang (N: 30.71-33.01; E: $\left.103.75-105.72^{\circ}\right)$, Sichuan, China. It is a subtropical monsoon climate zone where the annual precipitation is $826-1417 \mathrm{~mm}$, the annual temperature is $14.7-17.3^{\circ} \mathrm{C}$, there are $1300-1328 \mathrm{~h}$ of sunshine, and the frost-free period is 253-301 days. The soil of the experimental field was sand-loam soil according to the Food and Agriculture Organisation (FAO) soil classification standards; its bulk density was $1.1 \mathrm{~g} / \mathrm{cm}^{3}$ with a perennial moisture content of $9.2 \%-0.1 \%$, wilting point of $6.2 \%-8.5 \%$, organic matter content of $0.23 \mathrm{~g} / \mathrm{kg}$, and total Nitrogen, total Phosphorus, and total Potassium levels of 1.1, 0.22 , and $15.6 \mathrm{~g} / \mathrm{kg}$, respectively.

A total of 138 plots were designed for the 46 rice varieties with 3 replications of each by a randomized complete block design (RCBD). One hundred and fifty seeds of each rice variety were sowed in each assigned plot in the dry shed building (RRISWUST). At the three-leaf stage, some unhealthy rice seedlings were removed and 100 healthy rice seedlings were kept for each genotype. When $80 \%$ of the 100 rice seedlings were at the four-leaf stage, irrigation was stopped, and all water in the plots drained off. The biomass weight and plant height were measured and the number of leaves was counted every 7 days until all rice plants died. Based on these results, the 46 rice varieties classified into three groups and two varieties were selected as typical rice plants from each group (total of six varieties) for further research.

The selected varieties further underwent a pot planting experiment in the greenhouse of RRISWUST. A specially designed pot with an inner diameter of $50 \mathrm{~cm}$, outer diameter of $60 \mathrm{~cm}$, and height of $55 \mathrm{~cm}$ was used to carry out the further experiments. Sand-loam soil (similar to that used in the field experiment) was used to fill the inner pots, and water was used to fill the outer pots. Seventy-two pots were selected to plant rice of the six selected genotypes, with each genotype planted in twelve pots. Four rice seeds were sown in each pot and grown in well-watered conditions under 6-8 h of light, $20-25{ }^{\circ} \mathrm{C}$ temperature, and $70 \%-80 \%$ relative humidity. At the three-leaf stage, only one healthy seedling was kept in each pot, and when it reached the four-leaf stage, irrigation was stopped and all water was drained off from the pots. Afterward, three pots were selected to check the root distribution and three pots to check antioxidant enzyme activity in the roots and leaves. The remaining six pots were re-irrigated as rice wilted the first time. When the rice revived, irrigation was stopped and all water was again drained from the pots; as before, three pots were used for root distribution analysis and three pots for antioxidant enzyme activity analysis in roots and leaves.

\subsection{Samples and Measurements}

\subsubsection{Root Distribution}

When rice wilted the first time, three inner pots were taken out from the large external pots, and the inner pot was cut into three parts: the top layer $(0-10 \mathrm{~cm}$ depth), the middle layer $(10-30 \mathrm{~cm})$, and the bottom layer $(30-50 \mathrm{~cm})$. We washed and picked out all roots in the different parts; the root length and root weight (fresh) were measured and the root number was counted for each part. The roots less than $1 \mathrm{~cm}$ in length were excluded from the total root number, root length, and root weight. After washing, dry tissues were used to absorb all water that adhered over the root surface, then the root weights were measured for the different parts. When the rice wilted a second time, the process was repeated with three more pots to check the root number, root length, and root weight for the top, middle, and bottom soil layers.

\subsubsection{Enzymes in Roots and Leaves}

When rice wilted the first time, leaves and roots were sampled from three pots to examine the activity of antioxidant enzymes. Three top leaves and 10 roots (more than $10 \mathrm{~cm}$ in length) were collected from each pot into a $30 \mathrm{~mL}$ centrifuge tube and immediately frozen in liquid nitrogen. An extract was prepared via the method previously used by Swapna and Shylarajad [7] for analysis of 
antioxidant enzyme activity in the leaves and roots. The SOD activity was measured according to the method of Beauchamp and Fridovich [21], and POD and CAT activity were measured through the method of Kar and Mishra [22].

\subsubsection{DEEPER ROOTING 1 (DRO1) Gene Sequencing}

The DRO1 gene was identified from a breeding population derived from the cross between widely cultivated shallow-rooting IR64 rice and deep-rooting Kinandang Patong landrace that provided yield stability under drought; the author reported that a single $1 \mathrm{bp}$ deletion within exon 4 of the IR64 DRO1 gene results in forming a truncated protein and a reduced root angle in response to gravity while, on the contrary, the Kinandang Patong DRO1 gene promotes cell elongation at the root tip, causing downward growth that leads to the formation of a deep root system $[14,16]$. The DRO1 gene was sequenced in order to explore its role in the root distribution of typical rice varieties. Leaf tissues were sampled from typical rice varieties and immediately frozen in liquid nitrogen until DNA extraction. DNA was extracted from the leaf tissues by the cetyl trimethylammonium bromide (CTAB) method [23]. The DRO1 gene sequence and primers used were similar to those in Uga et al. [16]. The DNA samples were sent to the TSINGKE biological company (Chengdu, Sichuan, China) for DRO1 gene sequencing.

\subsection{Statistical Methods}

\subsubsection{Method to Calculate the Drought Tolerance Capacity of Rice}

Based on the dynamic changing of the biomass weight, height, and leaves of different rice genotypes under drought stress, the Complex Tolerance Index of Rice under Drought Environment (CTIRDE) was calculated by the following formula:

$$
\begin{gathered}
C T I R D E=H I \times 0.1+B I \times 0.3+L I \times 0.6 \\
H I=\frac{\sum\left(\frac{H_{i}-H_{i+1}}{D_{i}-D_{i+1}}\right)}{n-1} 0<i \leq 10 \\
B I=\frac{\sum\left(\frac{B_{i}-B_{i+1}}{D_{i}-D_{i+1}}\right)}{n-1} 0<i \leq 10 \\
L I=\frac{\sum\left(\frac{L_{i}-L_{i+1}}{D_{i}-D_{i+1}}\right)}{n-1} 0<i \leq 10
\end{gathered}
$$

where $H I$ is the height change index, $B I$ is the biomass weight change index, and $L I$ is the leaf change index of rice to drought stress. $H_{i}$ is the plant height of rice at the $i$ th measurement; $H_{i+1}$ is the plant height of rice at the $(i+1)$ th measurement. $B_{i}$ is the biomass weight of rice at the $i$ th measurement; $B_{i+1}$ is the biomass weight of rice at the $(i+1)$ th measurement. $L_{i}$ is the leaf number of the rice plant at the $i$ th measurement; $L_{i+1}$ is the leaf number of the rice plant at the $(i+1)$ th measurement. $D_{i}$ is the days of rice growth at the $i$ th measurement; $D_{i+1}$ is the days of rice growth at the $(i+1)$ th measurement.

\subsubsection{Methods for Data Analysis}

In the present study, three biological replicates of each experiment were performed and the mean was calculated from the three replicates. The data shown are means \pm SDs. Variance in the activity of antioxidant enzymes among different rice varieties was analyzed by one-way ANOVA using SPSS (Version 20, Chicago, IL, USA) and the least significant difference statistic test (LSD = 0.05). The correlations analysis was carried out using the Pearson correlation method in SPSS (Version. 20, Chicago, IL, USA). 


\section{Results}

\subsection{Complex Tolerance Index of Rice under Drought Environment (CTIRDE)}

Hybrid rice varieties displayed diverse response under the imposition of drought stress. The CTIRDE values varied from 0.84 to 0.55 , and rice varieties were categorized in three groups on the basis of these values. The CTIRDE values of the studied rice varieties ranging from 0.75 to $0.84,0.65$ to 0.75 , and 0.55 to 0.65 were considered tolerant $(\mathrm{C})$, semi-tolerant $(\mathrm{H})$, and sensitive (A), respectively. This screening identified 12 tolerant, 25 semi-tolerant, and 9 sensitive varieties (Figure 1). Deyou4727 and Chuanguyou208 were selected from the tolerant (C) group, Dexiang4103 and Rong18you447 were selected from the semi-tolerant $(\mathrm{H})$ group, and Byou2761 and Byou5768 were selected from the sensitive (A) group as typical rice varieties for further analysis of their drought tolerance capacity.

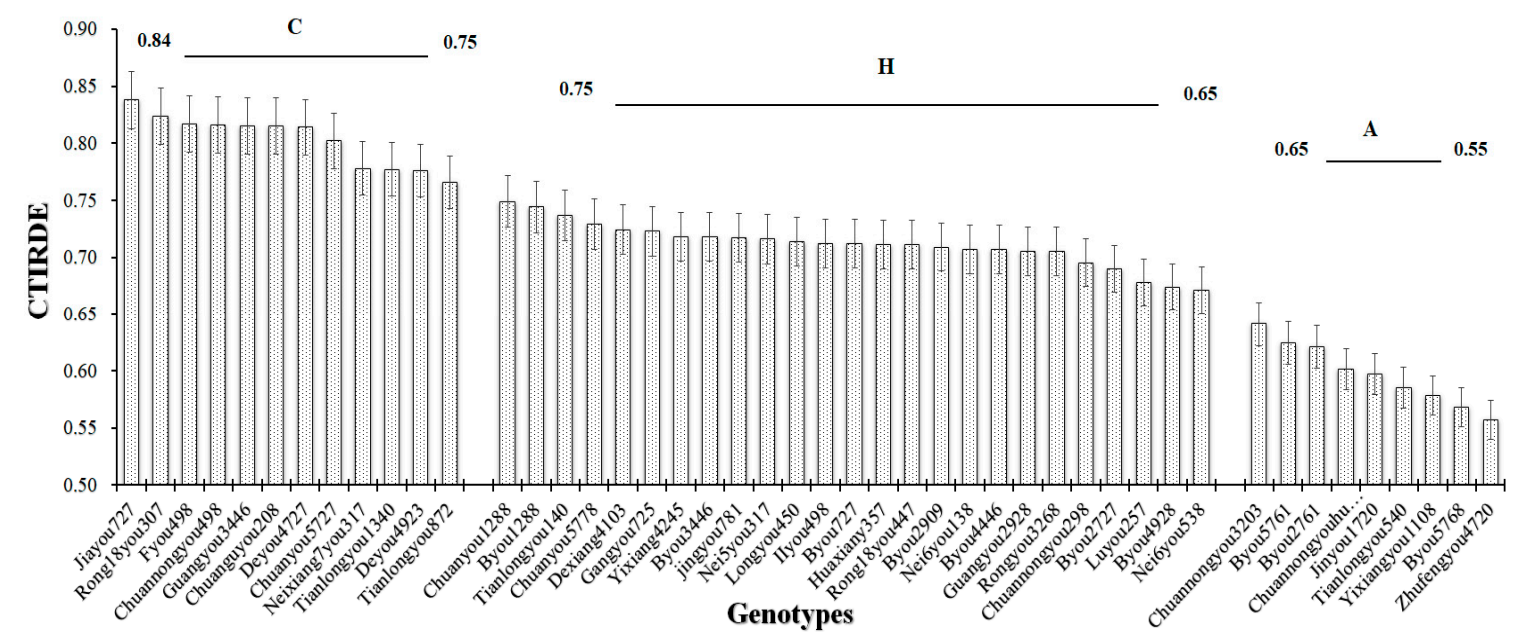

Figure 1. Forty-six rice varieties categorized into three groups on the basis of Complex Tolerance Index of Rice under Drought Environment (CTIRDE) values; rice varieties with CTIRDE values ranging from 0.75 to $0.84,0.65$ to 0.75 , and 0.55 to 0.65 were categorized into the tolerant group (C), semi-tolerant group $(\mathrm{H})$, and sensitive group $(\mathrm{A})$, respectively.

\subsection{Root Distribution Analysis}

Roots are one of the most important organs of rice; they help rice to be anchored in soil and to absorb water and nutrients from the soil. The present research was conducted to explore the role of rice roots in drought tolerance capacity by investigating the root distribution of typical rice varieties in different soil layers. Compared with that of the sensitive group (Byou2761 and Byou5768), the root length of the tolerant group (Deyou4727 and Chuanguyou208) increased by 171 and $489 \mathrm{~cm}$ in the 10-30 and 30-50 cm soil layers, respectively (Figure 2). However, this uptrend from the sensitive group to the tolerant group was not significant in the $0-10 \mathrm{~cm}$ soil layer. Root numbers of the tolerant group were 32 and 41 more than those of the sensitive group $(p<0.05)$ in the 10-30 and 30-50 cm soil layers, while the difference was not significant in the $0-10 \mathrm{~cm}$ soil layer (Figure 2 ). The root weight of the tolerant group was significantly heavier than that of the sensitive group in the 0-10 and 30-50 cm soil layers, while the difference was not significant in the 10-30 cm soil layer (Figure 2). Conclusively, root density did not differ significantly in the $0-10 \mathrm{~cm}$ soil layers, while the vertical distribution of roots differed significantly in the 30-50 cm soil layer. The tolerant group (Deyou 4727 and Chuanguyou208) of rice exhibited a much deeper root system than the sensitive group (Byou2761 and Byou5768); therefore, they could effectively use more water stored in the deeper soil layer and survive better under drought stress than other group varieties. 
(A) Comparison of root length
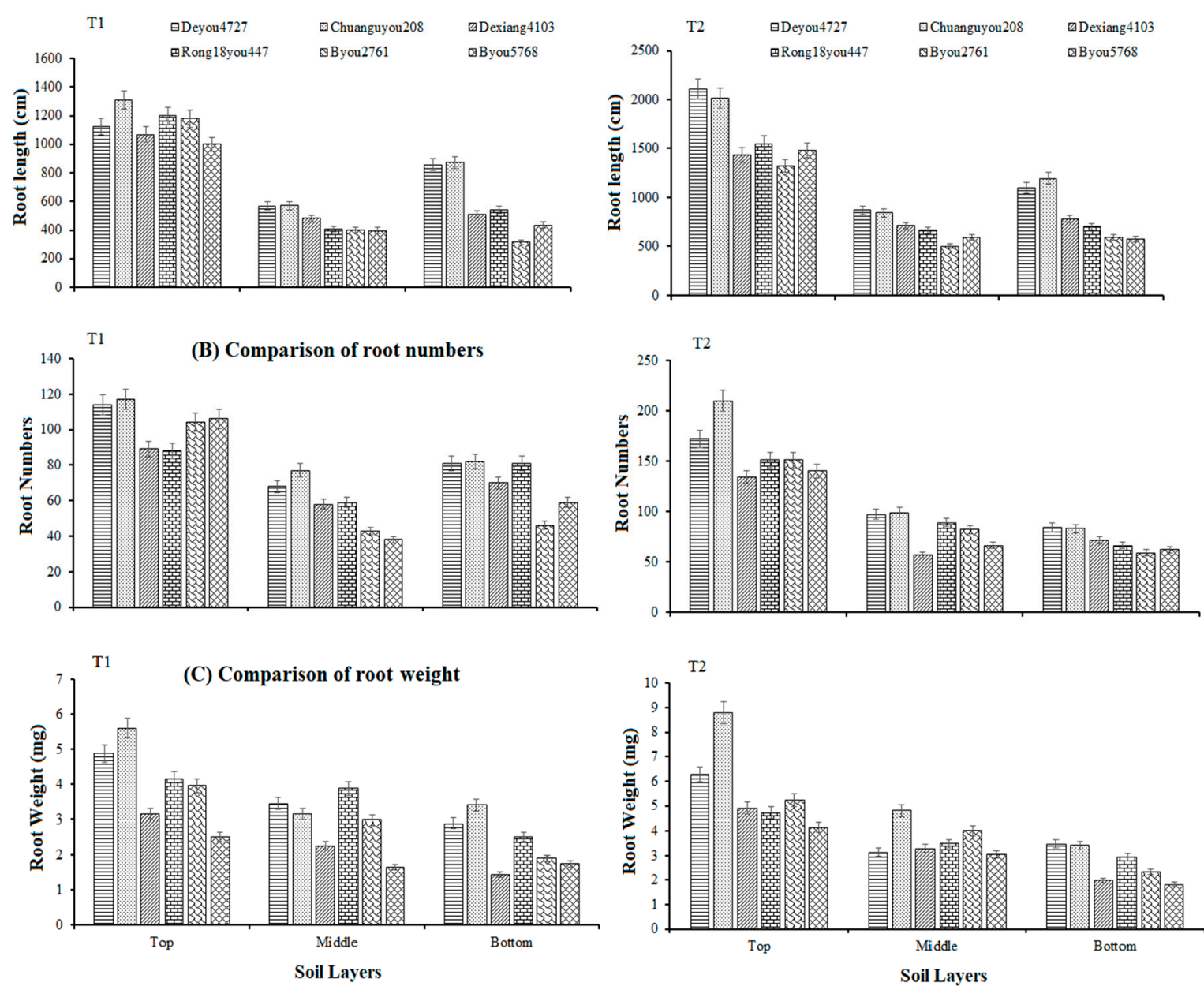

Figure 2. Comparison of Root distribution in different soil layers during two drought periods (T1 and T2). Top $(0-10 \mathrm{~cm})$, Middle $(10-30 \mathrm{~cm})$ and Bottom $(30-50 \mathrm{~cm})$ soil layer. (A) Comparison of Root length, (B) Comparison of Root number, (C) Comparison of Root weight.

\subsection{DEEPER ROOTING 1 (DRO1) Gene Sequence Analysis}

The DRO1 gene was previously reported to be involved in deep root development and to provide yield stability in a drought environment $[14,16]$. The DRO1 gene was sequenced in order to explore the genetic basis of variation in root development among different hybrid rice varieties. Sequencing of the corresponding gene revealed that the open reading frame (ORF) of the tolerant (Deyou4727 and Chuanguyou208) and sensitive groups (Byou2761 and Byou5768) exhibited single-nucleotide polymorphisms (SNPs) in exon 3. The tolerant group varieties (Deyou4727 and Chuanguyou 208) have " $\mathrm{C}$ " in exon 3 at the 752 bp region, while sensitive group varieties (Byou2761 and Byou5768) have "A" instead of "C" (Table 2). Interestingly, the semi-tolerant group (Dexiang4103, Rong18you447) was heterozygous $(\mathrm{H})$, containing both " $\mathrm{A}$ " and " $\mathrm{C}$ " in the same region (Table 2). The hybrid rice varieties having " $\mathrm{C}$ " in exon 3 showed the largest root growth angle with the horizontal axis, thus developing deeper roots as compared to other group varieties in a drought environment (Figure 3). 
Table 2. DRO1 gene sequencing of different hybrid rice varieties.

\begin{tabular}{ccccccccc}
\hline Materials & $\mathbf{5}^{\prime} \mathbf{U T R}$ & $\mathbf{5}^{\prime} \mathbf{U T R}$ & EXON 3 & EXON3 & EXON4 & EXON4 & $\mathbf{3}^{\prime} \mathbf{U T R}$ & Intron5 \\
\hline cDNA & 27 & 150 & 617 & 752 & 943 & 962 & $1133-1134$ & - \\
gDNA & 27 & 150 & 2096 & 2231 & 2513 & 2532 & $2909-2910$ & 2815 \\
Seq (+) & $\mathrm{A} / \mathrm{G}$ & $\mathrm{C} / \mathrm{T}$ & $\mathrm{T} / \mathrm{C}$ & $\mathrm{A} / \mathrm{C}$ & $\mathrm{A} /-$ & $\mathrm{C} / \mathrm{A}$ & $\mathrm{CT} /-$ & $\mathrm{A} / \mathrm{T}$ \\
\hline NPB & $\mathrm{A}$ & $\mathrm{C}$ & $\mathrm{T}$ & $\mathrm{A}$ & $\mathrm{A}$ & $\mathrm{C}$ & $\mathrm{CT}$ & $\mathrm{A}$ \\
Chuanguyou208 & $\mathrm{A}$ & $\mathrm{T}$ & $\mathrm{C}$ & $\mathrm{C}$ & $\mathrm{A}$ & $\mathrm{C}$ & - & $\mathrm{A}$ \\
Deyou4727 & $\mathrm{A}$ & $\mathrm{T}$ & $\mathrm{C}$ & $\mathrm{C}$ & $\mathrm{A}$ & $\mathrm{C}$ & - & $\mathrm{A}$ \\
Dexiang4103 & $\mathrm{H}$ & $\mathrm{T}$ & $\mathrm{C}$ & $\mathrm{H}$ & $\mathrm{A}$ & $\mathrm{C}$ & - & $\mathrm{A}$ \\
Rong18you447 & $\mathrm{A}$ & $\mathrm{T}$ & $\mathrm{C}$ & $\mathrm{H}$ & $\mathrm{A}$ & $\mathrm{C}$ & - & $\mathrm{H}$ \\
Byou2761 & $\mathrm{G}$ & $\mathrm{T}$ & $\mathrm{C}$ & $\mathrm{A}$ & $\mathrm{A}$ & $\mathrm{C}$ & - & $\mathrm{A}$ \\
Byou5768 & $\mathrm{H}$ & $\mathrm{T}$ & $\mathrm{C}$ & $\mathrm{A}$ & $\mathrm{A}$ & $\mathrm{C}$ & - & $\mathrm{A}$ \\
\hline
\end{tabular}
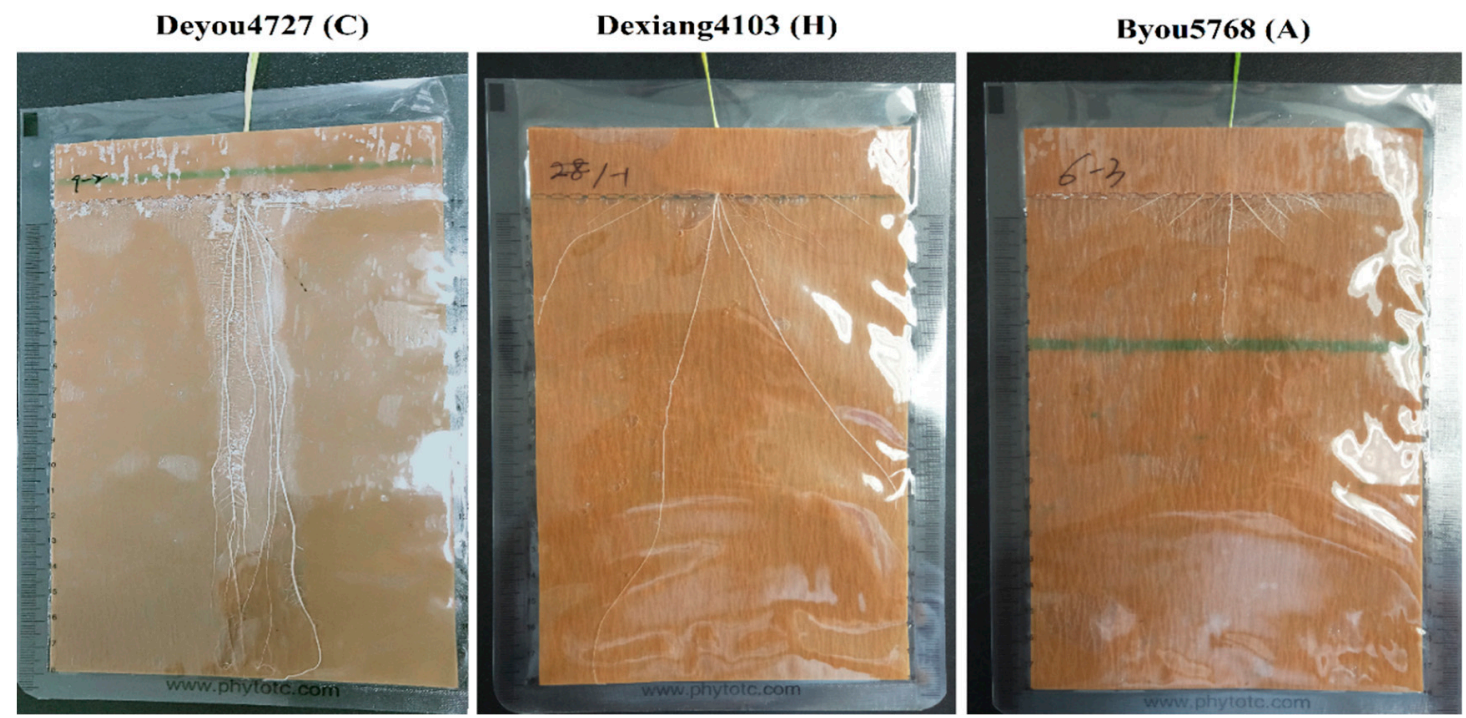

Figure 3. Variation in root length among different group varieties: Deyou4727 (C), Dexiang4103 (H), and Byou5768 (A).

\subsection{Antioxidant Enzyme Activity under Drought Stress}

In a drought environment, root SOD and POD activity showed a significant difference $(p<0.05)$ among tolerant (Deyou4727, Chuanguyou208), semi-tolerant (Dexiang4103, Rong18you447), and sensitive varieties (Byou2761 and Byou5768) (Table 3), while the difference in SOD activity in leaf was not significant among tolerant, semi-tolerant, and sensitive groups; similar results were found for POD activity in leaf. CAT activity differed significantly among some varieties both in leaf and root; however, this difference was not exactly significant among different groups (Table 3). The activity of antioxidant enzymes in roots, especially the activity of SOD and POD, was stronger than that in leaf. These results indicated that tolerant rice exhibited a strong antioxidant enzyme system, especially in terms of SOD and POD activity in root under drought stress. 
Table 3. Effect of drought stress on antioxidant enzyme activity in rice varieties. SOD, Superoxide dismutase; CAT, Catalase; POD, Peroxidase.

\begin{tabular}{ccccccc}
\hline \multirow{2}{*}{ Rice Varieties } & \multicolumn{2}{c}{ SOD } & \multicolumn{2}{c}{ CAT } & \multicolumn{2}{c}{ POD } \\
\cline { 2 - 7 } & Leaf & Root & Leaf & Root & Leaf & Root \\
\hline Deyou 4727 & $69.46 \mathrm{c}$ & $84.62 \mathrm{a}$ & $342.12 \mathrm{ab}$ & $494.62 \mathrm{c}$ & $7.90 \mathrm{a}$ & $32.02 \mathrm{a}$ \\
Chuanguyou 208 & $85.44 \mathrm{ab}$ & $87.51 \mathrm{a}$ & $412.08 \mathrm{a}$ & $815.18 \mathrm{a}$ & $10.48 \mathrm{a}$ & $22.13 \mathrm{~b}$ \\
Byou2761 & $53.43 \mathrm{~d}$ & $72.70 \mathrm{~b}$ & $304.13 \mathrm{~b}$ & $389.92 \mathrm{~d}$ & $7.75 \mathrm{a}$ & $17.12 \mathrm{c}$ \\
Byou5768 & $84.93 \mathrm{ab}$ & $75.59 \mathrm{~b}$ & $175.06 \mathrm{c}$ & $438.12 \mathrm{~cd}$ & $6.89 \mathrm{a}$ & $19.44 \mathrm{c}$ \\
Dexiang4103 & $81.04 \mathrm{~b}$ & $60.50 \mathrm{c}$ & $242.17 \mathrm{bc}$ & $449.56 \mathrm{~cd}$ & $5.79 \mathrm{a}$ & $11.41 \mathrm{~d}$ \\
Rong18you447 & $91.54 \mathrm{a}$ & $61.01 \mathrm{c}$ & $207.39 \mathrm{c}$ & $656.78 \mathrm{~b}$ & $7.98 \mathrm{a}$ & $10.88 \mathrm{~d}$ \\
\hline
\end{tabular}

In each column, values followed by different letters are significantly different at $p<0.05$ using the least significant difference statistic test (LSD).

\subsection{Correlation Analysis}

The correlation analysis showed that the root distribution in the $30-50 \mathrm{~cm}$ soil layer exhibited a good correlation with CTIRDE. Just as a significant correlation between root length and CTIRDE value was found in the $10-30 \mathrm{~cm}$ and $30-50 \mathrm{~cm}$ soil layers, similar results were found between root number and CTIRDE value (Table 4). The correlation between root weight and CTIRDE value was significant not only in the $30-50 \mathrm{~cm}$ soil layer but also in the $0-10 \mathrm{~cm}$ soil layer (Table 4). These results indicated that root amount, including root length, root number, and root weight, in 30-50 cm soil, plays an important role in the drought tolerance capacity of hybrid rice.

Table 4. Correlation analysis of CTIRDE values with root distribution and antioxidant enzymes.

\begin{tabular}{ccccccc}
\hline Trait. & Top Soil & Middle Soil & Bottom Soil & Antioxidant Enzymes & Leaf & Root \\
\hline Root length & -0.114 & $0.936^{* *}$ & $0.956^{* *}$ & SOD & -0.338 & $0.983^{* *}$ \\
Root number & 0.369 & $0.96^{* *}$ & $0.874^{*}$ & CAT & 0.668 & 0.242 \\
Root weight & $0.767^{*}$ & 0.511 & $0.748^{*}$ & POD & 0.648 & $0.890^{*}$ \\
\hline
\end{tabular}

The values shown are Pearson correlation coefficients, and significant correlations are indicated by * $(p<0.05)$ and ${ }^{* *}(p<0.01)$. Top soil, Middle soil, and Bottom soil represent soil layers of $0-10 \mathrm{~cm}, 10-30 \mathrm{~cm}$, and $30-50 \mathrm{~cm}$, respectively.

CTIRDE value has a significant correlation with SOD and POD activity (Table 4) in root, with correlation indices of 0.983 and 0.890 , respectively. However, there was no significant correlation between CAT activity and CTIRDE value, neither in leaf nor in root (Table 4). The activity of SOD, CAT, and POD in leaf all showed no significant correlation with CTIRDE value, though the correlation between enzyme activity and CTIRDE value reached 0.668 and 0.648 for CAT and POD, respectively (Table 4). These results suggested that the activity of SOD and POD in root plays a more important role in the drought tolerance of rice in comparison with that in leaf.

The correlation analysis showed that the DRO1 gene exhibited a positive correlation with the root length and this correlation was significant in the 10-50 cm soil layer (Table 5). Similarly, DRO1 displayed a positive correlation with root number and root weight which was significant in the $30-50 \mathrm{~cm}$ soil layer (Table 5). These findings indicated that the DRO1 gene has a sound correlation with the root distribution, particularly with deep root distribution.

A positive correlation was observed between the DRO1 gene and SOD activity both in leaf and root, and this correlation was significant for SOD activity in root (Table 5). Similarly, POD activity in root displayed a significant correlation with the DRO1 gene, though POD activity in leaf and root both positively correlated with the DRO1 gene (Table 5). The correlation between CAT activity and the DRO1 gene was not significant either in leaf or in root (Table 5). Overall, the DRO1 gene showed a good positive correlation with antioxidant enzyme activity, particularly with root antioxidant enzyme activity. 
Table 5. Correlation analysis of DRO1 with root distribution and antioxidant enzymes.

\begin{tabular}{ccccccc}
\hline Trait & Top Soil & Middle Soil & Bottom Soil & Antioxidant Enzymes & Leaf & Root \\
\hline Root length & 0.517 & $0.714^{*}$ & $0.857^{*}$ & SOD & 0.338 & $0.852^{*}$ \\
Root number & 0.266 & 0.496 & $0.825^{*}$ & CAT & 0.215 & 0.242 \\
Root weight & 0.309 & 0.684 & $0.774^{*}$ & POD & 0.548 & $0.763 *$ \\
\hline
\end{tabular}

The values shown are Pearson correlation coefficients, and significant correlations are indicated by * $(p<0.05)$. Top soil, Middle soil, and Bottom soil refer to soil layers of $0-10 \mathrm{~cm}, 10-30 \mathrm{~cm}$, and $30-50 \mathrm{~cm}$ in depth.

\section{Discussion}

As one of the most common environmental stresses, drought affects the growth and development of plants [24]. Drought resistance is a complex trait due to its interdependency on internal and environment factors, such as soil texture, root distribution, and water conditions. As an important organ used to absorb water and nutrients from soil, the roots, particularly deep roots, play a crucial role in a plant's drought resistance by avoiding drought through absorbing water from deep soil layers $[13,14,25]$. In the present study, the root distribution of different hybrid rice cultivars was tested in the top, middle, and bottom soil layers. A huge variation in root development was observed among different rice cultivars; these findings showed the importance of genotypic variability in root development as elucidated by earlier studies [6,26-28]. Tolerant cultivars (Deyou4727 and Chuanguyou208) developed a significantly deeper root system as compared with semi-tolerant (Dexiang4103, Rong18you447) and sensitive cultivars (Byou2761 and Byou5768), enabling these rice varieties to avoid drought through extracting water from deep soil layers. Our results are consistent with those of earlier studies on rice [14,16,29].

Numerous quantitative trait loci (QTLs) controlling root morphology have been mapped [30]; however, a limited number of studies have been conducted on QTLs regulating deep rooting in rice. Six major QTLs for deep rooting have been reported [14,16,25,31-33], and only DRO1 QTL, which controls root growth angle and eventually leads to the development of deep roots, has been cloned. Kinandang Patong (KP), carrying a functional allele of DRO1, has a deep root system, while IR64, carrying a non-functional allele of DRO1 (1 bp deletion in exon 4) has a shallow root system [16]. In the present research, we sequenced the DRO1 gene from typical hybrid rice varieties and found an SNP in exon 3. The sensitive group contained $\mathrm{A}$ and showed a small root growth angle, thus attaining only shallow rooting; the tolerant group contained $\mathrm{C}$ and displayed a larger root growth angle, hence attaining deep rooting; however, the semi-tolerant group contained both $\mathrm{A}$ and $\mathrm{C}$, exhibited an intermediate root growth angle, and accordingly developed a mixed roots phenotype (Table 2) (Figure 3). These results suggest that deep-rooting cultivars carry the functional allele of the DRO1 gene, while in the other two groups, the protein produced might not perform the normal function.

When plants are exposed to a drought environment, stomata are closed to reduce loss of water; this decreases carbon dioxide fixation and lessens $\mathrm{NADP}^{+}$regeneration [34]. Consequently, the production of ROS increases, leading to peroxidation of lipids, protein denaturation, DNA mutation, and cellular oxidative damage $[35,36]$. The induced activity of antioxidant enzymes in plants is a natural strategy to fight against oxidative damage in a harsh environment [37]. SOD is considered a key enzyme to minimize ROS by converting them to $\mathrm{H}_{2} \mathrm{O}_{2}$; later $\mathrm{H}_{2} \mathrm{O}_{2}$ is eliminated by CAT and POD activities [18,38]. Among the various antioxidant enzymes, CAT and SOD showed a relatively higher degree of induction in a drought environment. Similarly, POD activity was also induced; however, it was comparatively lower than CAT and SOD activities (Table 3). Our findings are consistent with those of a previous report on rice [7]: they reported higher CAT and SOD values as compared to POD values. Root SOD and POD activity displayed a significant difference among tolerant, semi-tolerant, and sensitive varieties (Table 3). Conclusively, these findings provide evidence that root SOD and POD activity play an important role in the drought tolerance capacity of rice varieties.

In general, water scarcity is a very serious problem for a rainfed cropping system, particularly for rice, which needs a large amount of water for growth and development [34]. Therefore, screening 
of drought-resistant rice varieties is a major challenge for future rice improvement programs. It has been reported that a drought environment causes a reduction in plant height, biomass weight, and other growth functions, which is reflected in overall growth reduction [7]. On the basis of plant height, biomass weight, and leaf number, we built the CTIRDE method to measure the tolerance variability of rice genotypes in a drought environment and provide selection criteria for screening rice germplasm for drought tolerance. The hybrid rice varieties showed enormous variation in CTIRDE values ( 0.55 to 0.84$)$, and three groups were identified: tolerant $(0.75$ to 0.84$)$, semi-tolerant $(0.65$ to $0.75)$, and sensitive (0.55 to 0.65). CTIRDE showed a good correlation with root distribution and enzyme activity, particularly the activity of POD and SOD in root and the root distribution in the $10-50 \mathrm{~cm}$ soil layer $(p<0.01)$. These results indicate that the CTIRDE method might be an effective and operable method to screen rice germplasm for drought tolerance.

\section{Conclusions}

The tolerant varieties developed a deeper root system as compared with sensitive varieties and showed relatively higher activity of POD and SOD enzymes in root in a drought environment; deep root distribution and higher activity of antioxidant enzymes in roots both have a significant correlation with the DRO1 gene. CTIRDE value, the activity of POD and SOD in roots, and root distribution in deep soil are some better agronomic traits which can be used to screen drought-tolerant rice for seasonal drought regions. Deyou4727 and Chuanguyou208 were identified as tolerant rice with deep root systems and can be used in the regions which often suffer from seasonal drought, such as the Sichuan Basin area. However, there remains a need to test these cultivars at different growth stages and under various water saving strategies before formulating final breeding decisions and crop management recommendations.

Supplementary Materials: The following are available online at http://www.mdpi.com/2073-4395/9/2/79/s1, Figure S1: Structure and fixings of designed pots system, Figure S2: Control system of designed pots system.

Author Contributions: Designed experiment and prepared original draft: X.W. and N.S.; Conducted experiment: M.W., L.L. and M.Q.; Collected and analyzed data: G.Y.; Provided experimental rice varieties: J.Q., K.J.; Review and editing: F.R.; Conceptualization and project administration: Y.H. and X.W.

Funding: This study was supported by the National Key Research and Development Program of China (No. 2016YFD0300210; No. 2017YFD0100206 and No. 2017YFD0301706) and Sichuan Science and Technology program (No. 18GJHZ0204).

Acknowledgments: We would also like to thank the reviewers who provided suggestions to improve this paper.

Conflicts of Interest: The authors declare no conflict of interest.

\section{References}

1. Zhang, J.; Zhang, S.; Cheng, M.; Jiang, H.; Zhang, X.; Peng, C.; Lu, X.; Zhang, M.; Jin, J. Effect of drought on agronomic traits of rice and wheat: A meta-analysis. Int. J. Environ. Res. Public Health 2018, 15, 839. [CrossRef] [PubMed]

2. Jing, R. Advances of research on drought resistance and water use efficiency in crop plants. Rev. China Agric. Sci. Technol. 2007, 9, 1-5.

3. Reynolds, T.W.; Waddington, S.R.; Anderson, C.L.; Chew, A.; True, Z.; Cullen, A. Environmental impacts and constraints associated with the production of major food crops in Sub-Saharan Africa and South Asia. Food Secur. 2015. [CrossRef]

4. Ndjiondjop, M.N.; Wambugu, P.W.; Sangare, J.R.; Gnikoua, K. The effects of drought on rice cultivation in sub-Saharan Africa and its mitigation: A review. Afr. J. Agric. Res. 2018, 13, 1257-1271. [CrossRef]

5. Singh, S.; Prasad, S.; Yadav, V.; Kumar, A.; Jaiswal, B. Effect of Drought Stress on Yield and Yield Components of Rice (Oryza sativa L.) Genotypes. Int. J. Curr. Microbiol. Appl. Sci. 2018, 7, 2752-2759.

6. Singh, B.; Reddy, K.R.; Redoña, E.D.; Walker, T. Screening of Rice Cultivars for Morpho-Physiological Responses to Early-Season Soil Moisture Stress. Rice Sci. 2017, 24, 322-335. [CrossRef] 
7. Swapna, S.; Shylaraj, K.S. Screening for Osmotic Stress Responses in Rice Varieties under Drought Condition. Rice Sci. 2017, 24, 253-263. [CrossRef]

8. Farooq, M.; Kobayashi, N.; Ito, O.; Wahid, A.; Serraj, R. Broader leaves result in better performance of indica rice under drought stress. J. Plant Physiol. 2010, 167, 1066-1075. [CrossRef]

9. Fukai, S.; Cooper, M. Development of drought-resistant cultivars using physiomorphological traits in rice. Field Crop. Res. 1995, 40, 67-86. [CrossRef]

10. Yue, B.; Xue, W.; Xiong, L.; Yu, X.; Luo, L.; Cui, K.; Jin, D.; Xing, Y.; Zhang, Q. Genetic basis of drought resistance at reproductive stage in rice: Separation of drought tolerance from drought avoidance. Genetics 2006, 172, 1213-1228. [CrossRef]

11. Kumar, R.; Sreenu, K.; Singh, N.; Jain, N.; Singh, N.K.; Rai, V. Effect of drought stress on contrasting cultivars of rice. Int. J. Trop. Agric. 2015, 33, 1559-1564.

12. Lipiec, J.; Doussan, C.; Nosalewicz, A.; Kondracka, K. Effect of drought and heat stresses on plant growth and yield: A review. Int. Agrophys. 2013, 27, 463-477. [CrossRef]

13. Gowda, V.R.P.; Henry, A.; Yamauchi, A.; Shashidhar, H.E.; Serraj, R. Root biology and genetic improvement for drought avoidance in rice. Field Crop. Res. 2011, 122, 1-13. [CrossRef]

14. Uga, Y.; Okuno, K.; Yano, M. Dro1, a major QTL involved in deep rooting of rice under upland field conditions. J. Exp. Bot. 2011, 62, 2485-2494. [CrossRef] [PubMed]

15. Fukai, S.; Pantuwan, G.; Jongdee, B.; Cooper, M. Screening for drought resistance in rainfed lowland rice. Field Crop. Res. 1999, 64, 61-74. [CrossRef]

16. Uga, Y.; Sugimoto, K.; Ogawa, S.; Rane, J.; Ishitani, M.; Hara, N.; Kitomi, Y.; Inukai, Y.; Ono, K.; Kanno, N.; et al. Control of root system architecture by DEEPER ROOTING 1 increases rice yield under drought conditions. Nat. Genet. 2013, 45, 1097-1102. [CrossRef] [PubMed]

17. Gill, S.S.; Tuteja, N. Reactive oxygen species and antioxidant machinery in abiotic stress tolerance in crop plants. Plant. Physiol. Biochem. 2010, 48, 909-930. [CrossRef]

18. Chutipaijit, S. Changes in physiological and antioxidant activity of indica rice seedlings in response to mannitol-induced osmotic stress. Chil. J. Agric. Res. 2016, 76, 455-462. [CrossRef]

19. Bian, S.M.; Jiang, Y.W. Reactive oxygen species, antioxidant enzyme activities and gene expression patterns in leaves and roots of Kentucky bluegrass in response to drought stress and recovery. Sci. Hortic. (Amsterdam). 2009, 120, 264-270. [CrossRef]

20. Nikolaeva, M.K.; Maevskaya, S.N.; Shugaev, A.G.; Bukhov, N.G. Effect of drought on chlorophyll content and antioxidant enzyme activities in leaves of three wheat cultivars varying in productivity. Russ. J. Plant. Physiol. 2010, 57, 87-95. [CrossRef]

21. Beauchamp, C.; Fridovich, I. Superoxide Dismutase: Improved Assays and an Assay Applicable to Acrylamide Gels1. Anal. Biochem. 1971, 287, 276-287. [CrossRef]

22. Kar, M.; Mishra, D. Catalase, Peroxidase, and Polyphenoloxidase Activities during. PLANT Physiol. 1976, 57, 315-319. [CrossRef] [PubMed]

23. Duan, Y.; Jiang, Y.; Ye, S.; Karim, A.; Ling, Z.; He, Y.; Yang, S.; Luo, K. PtrWRKY73, a salicylic acid-inducible poplar WRKY transcription factor, is involved in disease resistance in Arabidopsis thaliana. Plant. Cell Rep. 2015, 34, 831-841. [CrossRef] [PubMed]

24. Nahar, S.; Kalita, J.; Sahoo, L.; Tanti, B. Morphophysiological and molecular effects of drought stress in rice. Ann. Plant. Sci. 2016, 5, 1409-1416. [CrossRef]

25. Lou, Q.; Chen, L.; Mei, H.; Wei, H.; Feng, F.; Wang, P.; Xia, H.; Li, T.; Luo, L. Quantitative trait locus mapping of deep rooting by linkage and association analysis in rice. J. Exp. Bot. 2015, 66, 4749-4757. [CrossRef] [PubMed]

26. Kato, Y.; Abe, J.; Kamoshita, A.; Yamagishi, J. Genotypic variation in root growth angle in rice (Oryza sativa L.) and its association with deep root development in upland fields with different water regimes. Plant. Soil 2006, 287, 117-129. [CrossRef]

27. Asch, F.; Michael, D.; Abdoulaye, S.; Alain, A. Drought-induced changes in rooting patterns and assimilate partitioning between root and shoot in upland rice Drought-induced changes in rooting patterns and assimilate partitioning between root and shoot in upland rice. Field Crop. Res. 2005, 93, 223-236. [CrossRef]

28. Jaleel, C.A.; Manivannan, P.; Wahid, A.; Farooq, M.; Somasundaram, R.; Panneerselvam, R. Drought Stress in Plants: A Review on Morphological Characteristics and Pigments Composition. Int. J. Agric. 2009, 11, 100-105. 
29. Allah, A.; Badawy, S.A.; Zayed, B.A.; Gohary, A.A. El The Role of Root System Traits in the Drought Tolerance of Rice (Oryza sativa L.). World Acad. Sci. Eng. Technol. 2010, 68, 1378-1382.

30. Courtois, B.; Ahmadi, N.; Khowaja, F.; Price, A.H.; Rami, J.; Frouin, J.; Hamelin, C.; Ruiz, M. Rice Root Genetic Architecture: Meta-analysis from a Drought QTL Database. Rice 2009, 2, 115-128. [CrossRef]

31. Uga, Y.; Yamamoto, E.; Kanno, N.; Kawai, S.; Mizubayashi, T.; Fukuoka, S. A major QTL controlling deep rooting on rice chromosome 4. Sci. Rep. 2013. [CrossRef]

32. Uga, Y.; Kitomi, Y.; Yamamoto, E.; Kanno, N.; Kawai, S.; Mizubayashi, T.; Fukuoka, S. A QTL for root growth angle on rice chromosome 7 is involved in the genetic pathway of DEEPER ROOTING 1. Rice 2015. [CrossRef]

33. Kitomi, Y.; Kanno, N.; Kawai, S.; Mizubayashi, T.; Fukuoka, S.; Uga, Y. QTLs underlying natural variation of root growth angle among rice cultivars with the same functional allele of DEEPER ROOTING 1. Rice 2015. [CrossRef] [PubMed]

34. Nahar, S.; Sahoo, L.; Tanti, B. Screening of drought tolerant rice through morpho-physiological and biochemical approaches. Biocatal. Agric. Biotechnol. 2018, 15, 150-159. [CrossRef]

35. Sgherri, C.L.M.; Pinzino, C.; Navari-Lzzo, F. Sunflower seedlings subjected to increasing stress by water deficit: Changes in O2 production related to the composition of thylakoid membranes. Physiol. Plant. 1996. [CrossRef]

36. Smirnoff, N. The role of active oxygen in the response of plants to water deficit and desiccation. New Phytol. 1993. [CrossRef]

37. Luna, C.M.; Pastori, G.M.; Driscoll, S.; Groten, K.; Bernard, S.; Foyer, C.H. Drought controls on $\mathrm{H} 2 \mathrm{O} 2$ accumulation, catalase (CAT) activity and CAT gene expression in wheat. J. Exp. Bot. 2005, 56, 417-423. [CrossRef] [PubMed]

38. Carrasco-ríos, L.; Pinto, M. Effect of salt stress on antioxidant enzymes and lipid peroxidation in leaves in two contrasting corn, 'Lluteño' and 'Jubilee'. Chil. J. Agric. Res. 2014, 74, 89-95. [CrossRef]

(C) 2019 by the authors. Licensee MDPI, Basel, Switzerland. This article is an open access article distributed under the terms and conditions of the Creative Commons Attribution (CC BY) license (http:/ / creativecommons.org/licenses/by/4.0/). 